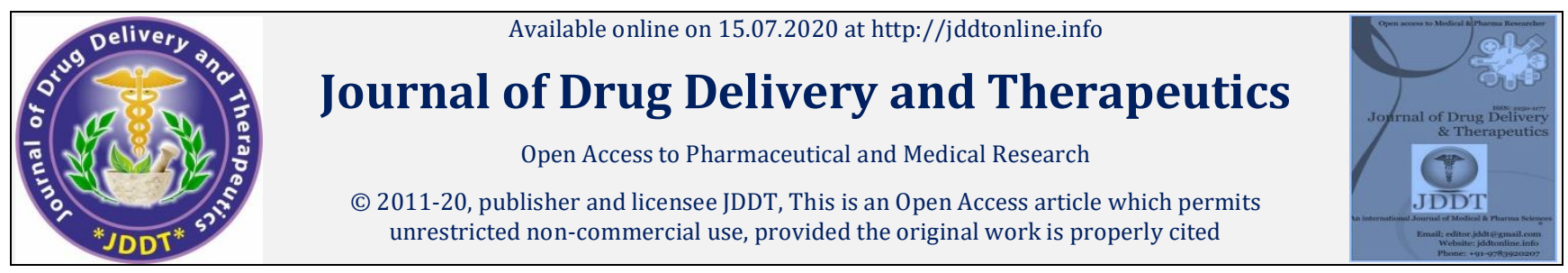

Open $\odot$ Access

Review Article

\title{
Epigenetics: Pharmacology and Modification Mechanisms Involved in Cardiac, Hepatic and Renal Disease
}

\author{
Waghmare Sagar. S. ${ }^{*}$, Bhusnure O.G. ${ }^{1}$, Mali M. R. ${ }^{2}$, Mule S.T. ${ }^{3}$
}

Department of Pharmaceutical Quality Assurance, Channabasweshwar Pharmacy College(Degree), Kava Road, Basweshwar Chowk, Latur, Maharashtra, India- 413512

\begin{abstract}
For a long time scientists have tried to describe disorders are due to genetic as well as environmental factors. In the past few years, revolution in technology that has made it possible to decipher the human genome. Epigenetics explains the capability gene expression regulation without modifying the genetic sequence. Epigenetic mechanisms are rooted changes in molecules, or nuclear characteristics that can al ter gene expression without altering the sequences of DNA, i.e. DNA methylation, histone modification, and non-coding RNAs. Learning of the fundamental epigenetic modification allowing gene expression as well as cellular phenotype are advanced that novel insights into the epigenetic control of cardiovascular disease, hepatic disease, as well as chronic kidney disease are now emerging. From a half of century ago, in human disease the role of epigenetics has been considered. This subject has attracted many interests in the past decade, especially in complicated diseases like cardiovascular disease, hepatic disease as well as chronic kidney disease. This review first illustrates the history and classification of epigenetic modific ations and the factors (i.e. genetic, environment, dietary, thought process and lifestyle) affecting to the epigenetics mechanisms. Likewise, the epigenetics role in human diseases is think out by targeting on some diseases and at the end, we have given the future perspective of this field. This review article provides concepts with some examples to describe a broad view of distinct aspects of epigenetics in biology and human diseases.
\end{abstract}

Keywords: - Epigenetics, DNA methylation, Histone modifications, microRNAs and Gene expression and Disease.

Article Info: Received 19 April 2020; Review Completed 12 June 2020; Accepted 26 June 2020; Available online 15 July 2020

\section{口] Cite this article as:}

Waghmare SG, Bhusnure OG, Mali MR, Mule ST, Epigenetics: Pharmacology and Modification Mechanisms Involved in Cardiac, Hepatic and Renal Disease , Journal of Drug Delivery and Therapeutics. 2020; 10(4):260-266 http://dx.doi.org/10.22270/jddt.v10i4.4148

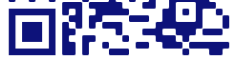

*Address for Correspondence:

Waghmare Sagar S, Department of Pharmaceutical Quality Assurance, Channabasweshwar Pharmacy College(Degree), Kava Road, Basweshwar Chowk, Latur, Maharashtra, India- 413512

\section{Introduction:}

In case of modern medicine genetics field has become an essential part in the 50 years therefore the structural model of DNA is illustrated by Watson and Crick. Advances have been made in identifying specific mutations related with some human diseases like cystic fibrosis as well as Huntington's chorea. Additional advances such as Human Genome Project, are giving new opportunities to develop better diagnostic tools and targeted gene therapies.1The Epigenetics term itself describes, as 'epi' means above or over in Greek, but it was Conrad Waddington who, in 1940, provided the first broad and operational definition of epigenetics it is nothing but the unusual interactions in genes and their products, that bring the phenotype into being".2 Conrad Waddington in the 1950s states that "an epigenetic feature is a stably heritable phenotype results in changes in a chromosome without changing the sequences in the DNA". ${ }^{3}$

\section{Epigenetics and Epigenomics:}

The epigenetic definitions state that the whole DNA content is exactly similar in somatic cells of one species, though gene expressions patterns have number of differences in various cell types that can be inborn clonally. ${ }^{4}$ Epigenetics have an tremendous effect on medicine. Epigenetics is nothing but the study of heritable alteration in gene functions that do not changes the DNA sequence but it can provide a one more layer of transcriptional control that control how genes are explicit. 5

The term "epigenetics" has been defined for decades as a alteration in the state of expression of a gene (or a feature) that does not contain a mutation but that is nonetheless rooted (at least through a mitotic division) in the absence of the signal or event that begins the change, the newer term "epigenomics" for our knowledge never been formally defined" Epigenomics" on the genome-wide level search 
communities has been widely accepted operationally to indicate studies that focuses on the analysis of DNA methylation, histone modifications, and noncoding RNAs. ${ }^{6}$

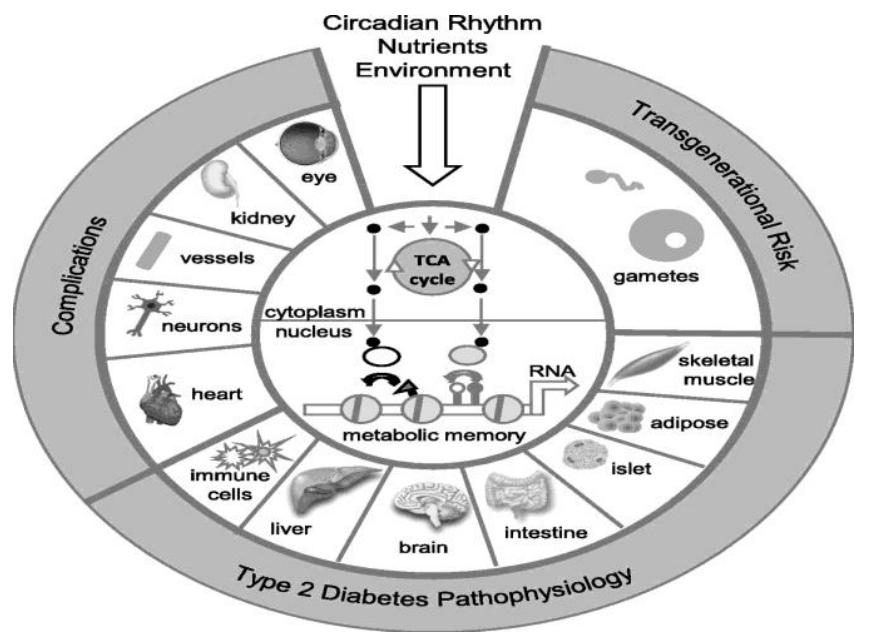

Figure1: Effects of epigenetics on epigenomics and occurrence of diseases. ${ }^{7}$

An Epigenetics mechanism describes that enable cells to respond quickly to environmental alteration and provide a link between genes and environment. Variation in the epigenetic modification of genes can describe a larger part of the phenotypic fluctuations observed in humans than differences in genotype alone. ${ }^{8}$ The current work focuses on epigenetic mechanisms of epigenetics in disease condition, for normal growth, development and homeostasis epigenetic processes are essential. ${ }^{9}$ A combination of stochastic events including both genetic as well as environmental factors (e.g., diet, smoking, obesity and stress), which, at the molecular level, cause alteration in gene expression and the aging process of organism. For example, aging of the brain is accompanied by changes of gene expression encoding proteins involved in stress responses, inflammatory responses and neuropeptide metabolism while the elderly heart has an altered transcription profile that leads to disability of cardiac function. ${ }^{10}$

In the past decade various studies have strongly implicated epigenetic mechanisms in controlling the gene expression changes regulating several aging-related diseases like cancer and cardiac failure and in promoting the gene expression changes are responsible for the aging process of different tissues. Therefore, during aging process cells more prone to the transcriptional changes responsible for aging-related diseases due to the alteration of epigenetic mechanism. In this review, we will discuss the possible role of epigenetics in controlling the onset of two aging-related diseases like cancer and cardiovascular disease. 11

\section{Mechanism of Epigenetics}

The major epigenetic controlling mechanisms of mammalian cells include-

1. DNA methylation,

2. posttranslational histone modifications (PTMs) and

3. RNA based mechanisms including those controlled by the better characterized small non-coding RNAs (sncRNAs).

MicroRNAs (miRNAs) and long non-coding RNAs (lncRNAs) are newly showing their potential as biomarkers.

\section{DNA methylation:-}

The DNA methylation is nothing but fairly stable epigenetic changes which consist of the covalent binding of a methyl group to the 5' carbon of cytosine. The CpG-rich islands contain $40 \%$ of genes and up to $70 \%$ of all CpG dinucleotides in the genome are methylated. Regulation of gene expression by changing the transcriptional machinery accessibility to DNA is the significant function of DNA methylation. ${ }^{12}$

High stability of DNA methylation status and it not only serves as a special epigenetic memory of specific cells over a all periods in the cell cycle but also regulate the gene expression and histone codes activity. Acceleration of DNA methylation process accelerated at $\mathrm{CpG}$ sites and mediated by DNA methyl transferase enzymes such as DNMT1, DNMT3a, and DNMT3b.S-adenosyl methionine act as an important methyl group donor inside the cell. Folic acid and B12 play the important roles in re-methylation or the attraction of de-methylated form of S-adenosyl methionine via active and passive mechanisms. ${ }^{13,14}$ In the initial years of life level of nutrition could impact on the DNA methylation pattern and level of gene expression in adulthood. 15

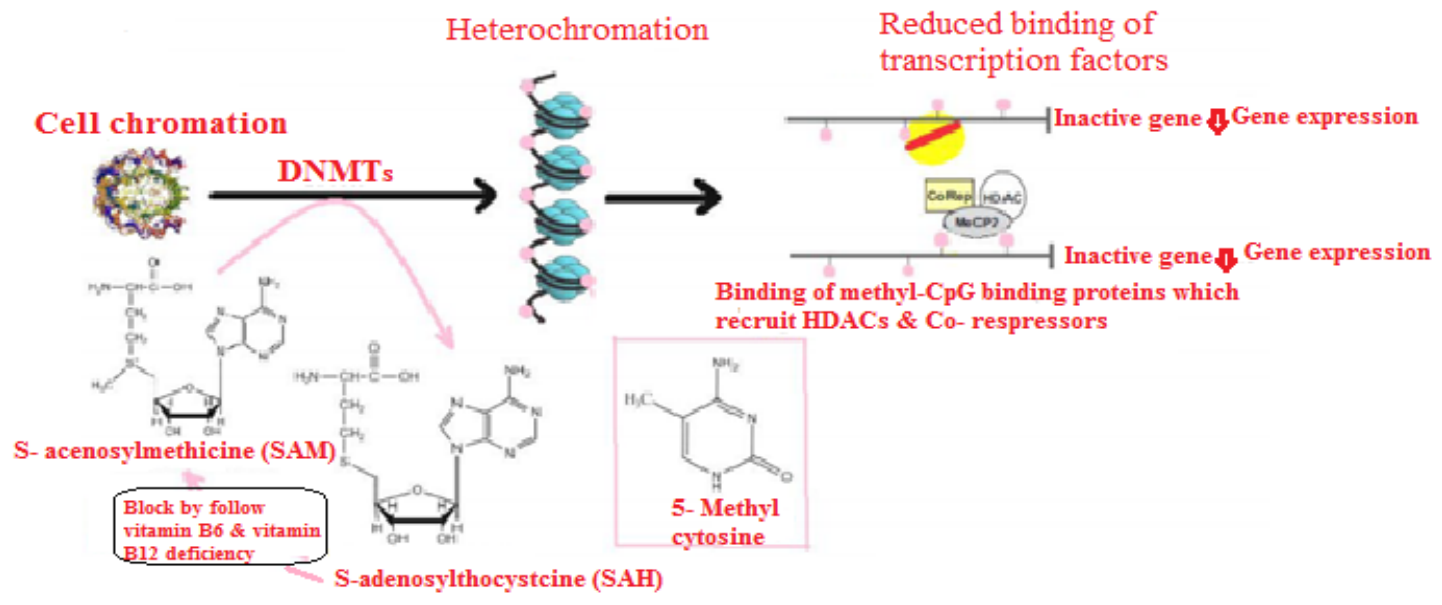

Figure 2: DNA methylation 16 


\section{Histone modifications:-}

Histone modification regulating the gene expression via chromatin remodeling and it includes acetylation, methylation, phosphorylation, ribosylation, ubiquitylation, sumoylation, and citrullination. Acetylation is has mediated through five families of mammalian histone acetyltransferase enzymes. ${ }^{17}$

Histone are that are essential components of nucleosomes structure in eukaryotic cells it is nothing but a small (11-22 $\mathrm{kDa}$ ) nuclear proteins hence DNA wraps around an octamer of the core histones $\mathrm{H} 2 \mathrm{~A}, \mathrm{H} 2 \mathrm{~B}, \mathrm{H} 3$, and $\mathrm{H} 4$, it helps in constructing the fundamental unit of chromatin.18 Due to PTMs, histone proteins play a essential role in the regulation of chromatin which control the binding of other proteins called readers. This evidence gives a idea that extracellular histones contribute to human disease because they are cytotoxic for a wide array of human cells and human tissues ${ }^{19}$ by performing several in vitro and in vivo experiments that showed after binding to phospholipids circulating histone can damage cell membranes, disruption of $\mathrm{Ca} 2+$ influx is produced and it leads to the release of other intracellular mediators that results in cell death. ${ }^{20}$

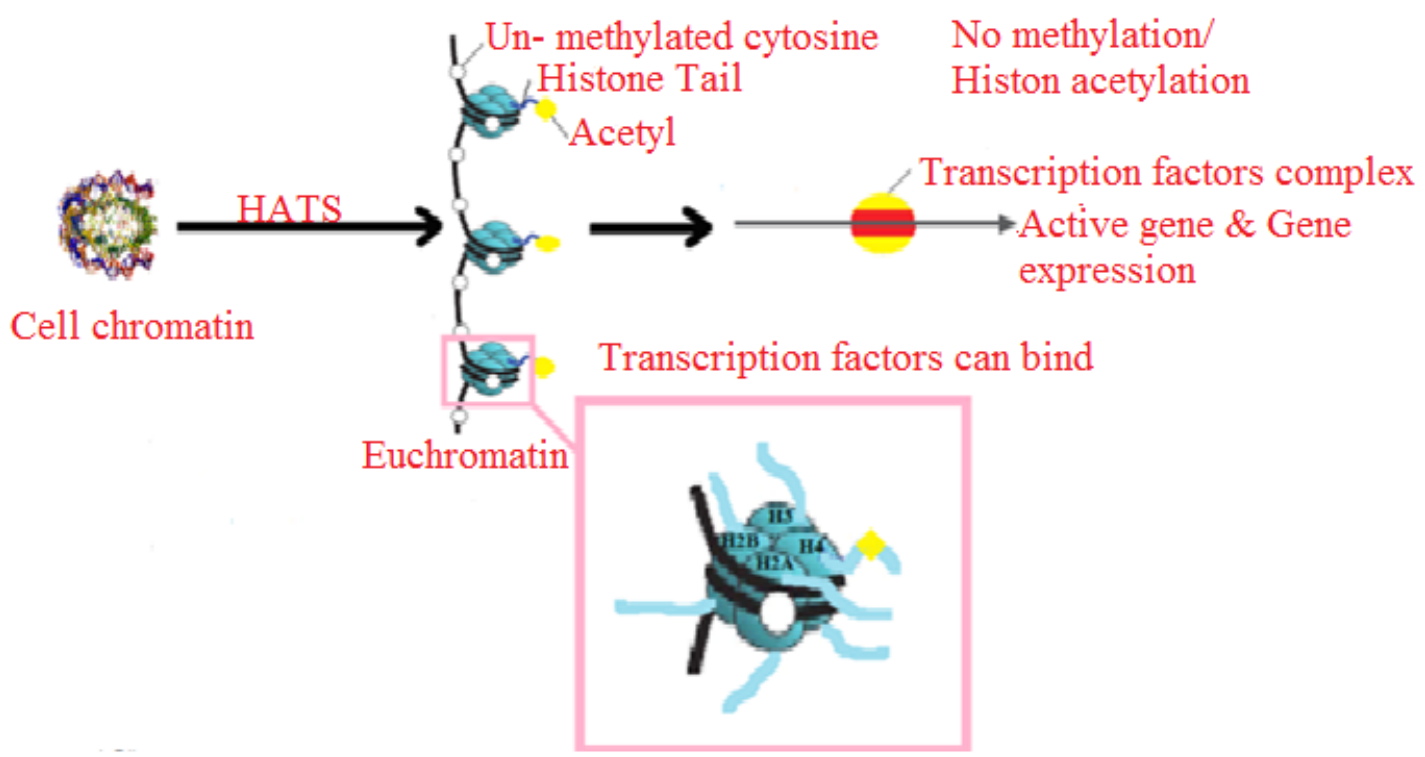

Figure3: Histone modification ${ }^{21}$

\section{3. miRNAs:-}

miRNAs are a class of conserved, short (18-24nt). At the posttranscriptional level non-coding RNAs that have ability to control the gene expression in distinct biological networks. In recent years miRNAs have potential to be used as biomarkers. $^{22}$ Recent studies is proposing epigenetic biomarkers mainly based upon circulating miRNAs as biomarkers of various disease conditions [e.g., cardiac disease,
Neurodegenerative and psychological disorders, chronic kidney disease and liver disease, among others].

miRNAs are considered as a member of the noncoding RNAs about 17 to 25 nucleotides that can carried out a various biological activities. About $60 \%$ of protein-coding genes in human is regulated by the miRNAs, 23 and these miRNAs are adjusted epigenetically adjusted by methylation in $\mathrm{CpG}$ islands or histone modifications or both of them.24, 25

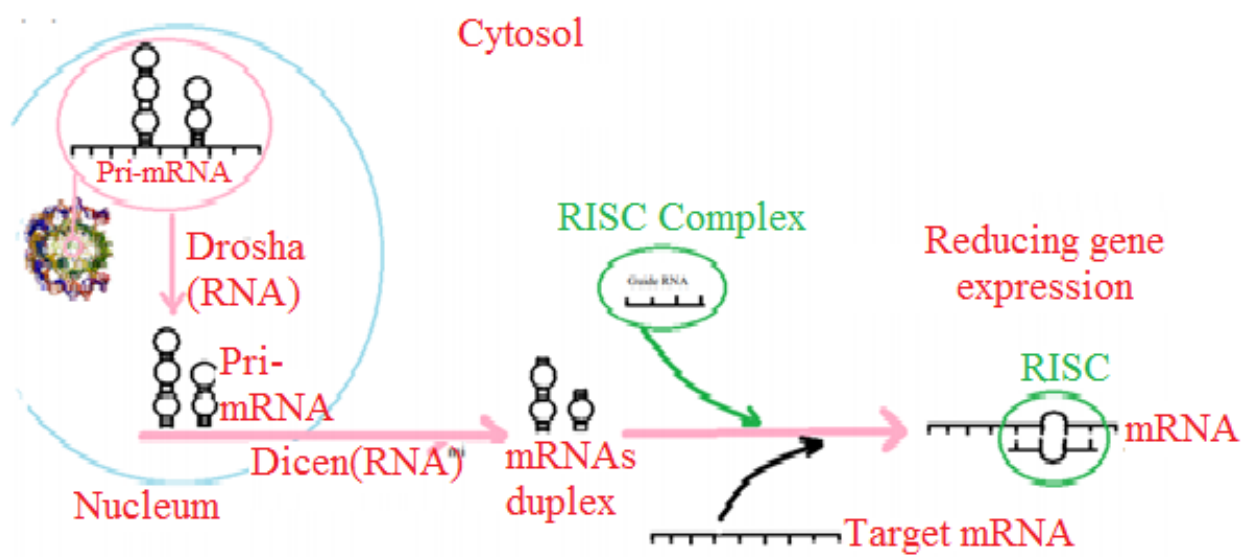

Figure 4: miRNA26 


\section{Factors affecting epigenetics}

There are number of factors which impact on epigenetics but mainly five factors which alter the epigenetic mechanism includes
i. Genetic factors
ii. Dietary factors
iii. Environmental factors
iv. Thought process
v. Lifestyle

\section{i. Genetic factors :-}

- Heredity: - The transfer of genes from one generation to the next generation. You inherit your parents' genes is known as heredity. It is helps to make you the person you are today: for example- short or tall, with black hair or blond, with brown eyes or blue. 27

\section{ii. Dietary factors:-}

- Diet also responsible for epigenetic changes. Dietary components have potential to overcome the disease and promote overall individuals health. $28,29,30,31$

\section{- $\quad$ Epigenetic diet compounds -}

Dietary Polyphenols: such as tea polyphenols (i.e., epicatechin, epicatechin-3-gallate, epigallocatechin and epigallocatechin-3-gallate),

Resveratrol and curcumin: It act as histone modifiers and it has potential as anticancer therapeutic as well as chemopreventive agents and have ability to inhibit the DNA methylation process.

Isoflavones: such as genistein are found in soybeans, fava beans and kudzu and it have anticancer properties that involved in DNA methylation process.

Isothiocyanates: such as sulforaphane can impact on the epigenome.

Other dietary factors: Those dietary components found in Brazilian nuts, chicken, cereals, coffee, cashews, garlic, parsley, milk thistle and rosemary have a epigenetic targets in cancer. Also have beneficial effects on the epigenome, are related with harmful epigenetic modifications. ${ }^{32}$

\section{iii. Environmental factors :-}

- "Environmental factors also responsible for the epigenetic changes. ${ }^{33}$ for example - vitamin B may defend against epigenetic effects on pollution and also prohibit the harmful effects that particular matter has on the body. 34

- Numerous environmental factors that have been associated with either global or site-specific DNA methylation alterations. The field of epigenetics has mainly focused on environmental factors such as nutrients and chemical contaminants. ${ }^{35}$

- Recently life nutrition also produces long-term changes in DNA methylation that impact on individual health as well as age-related diseases all over life. 36,37

- Psychological stress studies have indicated that DNA methylation is susceptible to stressful environmental exposures in early development as well as later in life. ${ }^{38,39,40,41,42,43}$

\section{iv. Thought process:-}

- A life of happiness and positive thoughts change future generations. Our thoughts and actions can alter the epigenetic mechanism.

- It's been shown just thinking about something can cause your brain to release neurotransmitters, chemical messengers that allow it to communicate with parts of itself and your nervous system. ${ }^{44}$

\section{Lifestyle:-}

- Various lifestyle factors such as nutrition, behavior, stress, physical activity, working habits, smoking and alcohol consumption. Environmental and lifestyle factors may alter the epigenetic mechanisms. ${ }^{45}$

- These factors leave epigenetic marks on our DNA that leads to the alteration of gene expression. ${ }^{46}$

\section{$>$ Epigenetics in Cardiovascular Disease}

Recent data associated DNA methylation, as measured in peripheral blood leukocytes; with clinical cardiovascular disease $^{47}$ found lower DNA methylation content in peripheral blood leukocytes from patients with atherosclerotic cardiovascular disease. From the aging study it has been found that lower LINE-1 methylation in peripheral blood leukocytes is a predictor of incidence and mortality from ischemic heart disease and stroke. ${ }^{48} \mathrm{Global}$ methylation measures gives average estimates of methylation across the genome do not have the resolution needed to target individual genes or gene sequences responsible for cardiovascular disease. ${ }^{49}$

\section{i. Heart failure:-}

Genetic predisposition and multiple environmental factors results in heart failure. In a patient with HF, Movassagh and colleagues reported that three angiogenesis-related genes were disccriminatory methylated. In the last stage of due to the altered epigenomics of the three genes may reflect common epigenetic pathways in vasculature and heart remodeling. ${ }^{50}$ In case of heart failure histone modifications and Micro-RNAs also have significant importance in epigenetics. ${ }^{51,52}$

\section{ii. Hypertension:-}

One of the biggest risk factor for cardiovascular disease development is hypertension. Hypertension is not effectively overcome in most of the patients which leads to many cardiovascular complications. Complex interactions between different environmental factors and genes results in hypertension and epigenetic mechanism is implemented to treat the hypertension. ${ }^{53,54}$ Number of factors causing hypertension such as autonomic, renal, vessel diameter/compliance and neuroendocrine.

\section{iii. Congenital Heart Disease}

Congenital heart disease (CHD) represents a large proportion of significant birth defects, occurring in approximately 8 per 1000 live births. ${ }^{55}$ Monogenic causes have been identified but most CHD is considered to be multifactorial with phenotypic differences noted between individuals in the same family or even with the same genetic defect (e.g. trisomy 21 where only $\sim 50 \%$ of individuals are born with CHD. A possible role for epigenetics in the etiology of CHD could be the dysregulation of DNA methylation during different stages of embryonic growth that could lead to the inappropriate silencing of tissue-specific gene expression and a resulting increased risk for cardiac malformation. ${ }^{56}$ 


\section{Epigenetics in liver Disease}

Alteration in epigenetics consequently promote a number of human diseases for example- fetal, and liver diseases ,alcohol spectrum disorders, various types of cancer, neuropsychiatric disorders. ${ }^{57}$ The second largest organ in the body is liver which performs a various biological functions. The common liver diseases are alcohol related and non-alcohol related liver diseases, viral-mediated liver diseases (Hepatitis A, B and C), fatty liver disease, Chronic liver diseases which needs longterm therapy.58 Effective treatment and prevention is necessary to reduce the mortality and economic burden caused by the liver diseases worldwide. Epigenetic regulatory mechanisms offer new therapeutic potential to treat these diseases.

\section{i. Hepatocellular Carcinoma}

In the world 250,000 to 1 million deaths annually are only because of hepatocellular Carcinoma (HCC) is the fifth most common cancer in the world that causes. ${ }^{59}$ There are number of risk factors for hepatocellular carcinoma including diabetes, and obesity, dietary exposure to aflatoxins ,hepatitis B virus (HBV) and hepatitis C virus (HCV) infections, smoking, alcohol.60 Epigenetic changes causes HCC metastasis, DNA methylation, histone modification, invasion, and dissemination encompass noncoding RNAs regulation and all these changes are associated with initiation and progression of hepatocellular carcinoma. ${ }^{61}$

\section{ii. Liver Fibrosis:-}

Recently it is well documented that cellular phenotype is at least in part under control of chromatin configuration at key regulatory genes, with the help of epigenetic mechanisms. ${ }^{62}$ 'epigenetics' describes that reversible changes in gene expression that can be inherited via cell division that do not involve alterations of DNA sequence. 63 Epigenetic mechanisms regulate the chromatin structure, modifications and the initiation of transcription and their co-factors that dictate the rate at which a gene is actively transcribed.64,65,66,67 Here, we consider the epigenetic mechanisms involved in the pathogenesis of liver fibrosis, as well as examine recent advancements, approaches and strategies used in the field of epigenetic for the treatment of liver fibrosis. ${ }^{6} 8$

\section{iii. Alcoholic Liver Disease:-}

In recent studies, it has been documented how epigenetic factors can impact on the function and expression of several genes. ${ }^{69}$ Alcohol consumption is responsible for $3.8 \%$ of global mortality and $4.6 \%$ of disability-adjusted life-years (DA-LYs) lost due to premature death. From the meta-analysis it has been found that risks of mortality is increased from liver cirrhosis among men and women drinking 12-24 g of ethanol per day. ${ }^{70}$ Due to the excessive consumption of alcohol it causes exposes the liver cells exposed to a elevated levels of ethanol, which can lead to a class of clinical conditions identified as alcoholic liver disease (ALD). ${ }^{71}$

Identification of epigenetic factors can be important not only for the screening of individuals at risk but also for the study of the epigenetic modification mechanisms underlying ALD. ${ }^{72}$

\section{$>\quad$ Epigenetics in kidney diseases}

From the emerging evidence recommend that epigenetic changes are involved in the pathogenesis of diseases predisposing to chronic kidney disease (CKD). DNA hypermethylation has been associated with predisposition to, and progression of, atherosclerosis. ${ }^{73}$ A recent study DNA methylation levels in more than 14,000 genes between African-American end stage renal disease patients and his panic diabetes it shows that DNA methylation differences were related with disease treatment. ${ }^{74}$ By changing the DNA methylation and histone acetylation epigenetic modulations of gene expression that might predispose to hypertension. ${ }^{75}$

Based on the number of experimental studies it describes that local, gene-specific alterations in DNA methylation may play an essential role in the treatment of chronic kidney disease. From some evidence it was recommend that RNA interference is mainly essential for the development and progression of kidney disease. 76

\section{i. Renal cancer:-}

Over the last three decades renal cancer rising steadily and currently, it is 9th most common cancer in Europe. ${ }^{77}$ The diagnosis of renal cell cancer depends upon early detection of the tumor. Sometimes, clinical signs and symptoms are often not useful in an early prognosis of cancer, therefore the classic symptoms like haematuria, palpable flank mass and pain and are generally related with advanced stage of the disease.78.79, 80 Arai E, 200981 reported that more malignant renal cancer is generated mainly due to the alterations of DNA methylation in the precancerous kidney cortex tissue. Recently, it is admitted that DNA methylation is the interplay between genetics and epigenetics that leads to tumour genesis and the development of cancer. This interplay have recently been elegantly demonstrated by 82 who identified mutations in genes that encode enzymes, alter chromatin structure and transcriptional control and therefore which demethylate or methylate key lysine residues of histones and it leads to the development of renal cell cancer. 82

Epigenetic mechanisms can be involved in the treatment of these neoplasms as well. ${ }^{83}$

\section{ii. Chronic Kidney Disease (CKD)}

There is considerable evidence showing the role of epigenetic mechanisms in the development of chronic kidney disease. Difference in DNA methylation pattern between normal and diseased kidneys identified in renal fibroblasts is noticed in previous study. ${ }^{84}$ Fibroblast multiplication is regulated by DNA methylation and leads to renal fibrogenesis. For example- The study of experimental murine models treated with 5azacytidine, it results in protection from renal fibrosis. In also demonstrated that hypermethylation of RAS protein activator like- 1 was related with the renal fibrogenesis. ${ }^{84}$ various histone modifications in the human kidney have not been assessed with reference to chronic kidney disease.

\section{Future Prospective:}

In an individual's lifetime DNA methylation and histone modifications might help to describes how environmental and lifestyle factors can impose aberrant gene expression patterns. For example, in the pathogenesis of cardiac lesions like, among others, atherosclerosis, arrhythmias, thrombosis and left ventricular dysfunction, DNA and histones play essential roles by reducing the DNA-histone complex may constitute a viable goal for prevention of various cardiac complications. ${ }^{85} \mathrm{New}$ approaches have brought different clinical trials and have been explored recently targeted for the treatment of cardiovascular disease, liver disease and renal disease.86 However, a detailed genetic background evaluation helps the physicians to design the best therapeutic approach for each disease. For example - microRNAs involved in the proinflammatory switch in macrophages and Kupffer cells will be more efficient and then a steroid-based treatment and will bare less side effects. Moreover, it has to be considered that epigenetic factors can be regulated by environmental factors, i.e. diet and medications, and since represent an ideal genetic therapy target. 


\section{Discussion:}

At the transcriptional and post-transcriptional levels or at the translation level and post-translational modifications epigenetic mechanisms can influence the gene activity. Potentially broad spectrum effects of epigenetic mechanism can be affected by both genetic and environmental factors could results in more varieties of cell differentiations, morphogenesis, variability, and adaptability of an organism. ${ }^{87}$ The epigenetics covers the DNA modifications, histones and DNA-binding proteins, which are important in regulating changes in chromatin structure without any alteration in the sequence of nucleotide in DNA. Also, these alterations could be transferred from one generation to the next generation. The overall studies have shown that exercise and lifestyle modifications including nutritional habits are first protective measures for decreasing the risk of disease. ${ }^{88}$ In the pathogenesis of cardiovascular disease, hepatic disease and renal disease Non-coding RNAs were found to be essential and it also offers the possibility of operating as diagnostic and prognostic biomarkers. ${ }^{89}$ To improve our understanding of the involvement of IncRNA in regulating gene expression changes underlying heart, liver as well as kidney failure further studies on epigenetics is needed. 88

\section{Conclusion:}

The epigenetics controlling the alteration in gene expression which influence on many different human cardiac, hepatic and renal diseases. Epigenetics helps to explain the complex interactions between genes and environment and understanding of disease by providing a new conceptual framework. Over the life course epigenetic factors potently influence epigenetic variations and changes in gene expression. Epigenetic mechanisms in various diseases play a significant role in controlling the altered gene expression, which is also critical for disease development. These epigenetic modifications may serve as signatures to diagnose the disease and also may provide a promising scope to develop new drug targets to treat these diseases.

\section{References:}

1. Rodenhiser D, Mann M, Epigenetics and human disease: translating basic biology into clinical applications, 2006 174(3):341-348.

2. Waddington $\mathrm{CH}$, Organisers and Genes, Cambridge University Press; Cambridge: 1940; 1-3.

3. Berger SL, Kouzarides T, Shiekhattar R, Shilatifard A, An operational definition of epigenetics, Genes and development, 2009; 23(7):781-783.

4. Felsenfeld G, A brief history of epigenetics, Cold spring harbor perspectives in biology 2014; 6(1): doi: 10.1101/ cshperspect.a018200.

5. Egger G, Liang G, Aparicio A, Jones PA, Epigenetics in human disease and prospects for epigenetic therapy, Nature, 2004; 429(6990):457-463.

6. Deans C, Maggert KA, What do you mean, "epigenetic"? Genetics2015; 199:887-896.

7. Sapienza C, Lee J, Powell J, DNA methylation profiling identifies epigenetic differences between diabetes patients with ESRD and diabetes patients without nephropathy, Epigenetics, 2011; 6:2028.

8. Turan N, Katari S, and Coutifaris C, Sapienza C, Explaining interindividual variability in phenotype: is epigenetics up to the challenge? Epigenetics, 2010; 5:16-19.

9. Skinner MK, Manikkam M, Guerrero-Bosagna C,Epigenetic transgenerational actions of environmental factors in disease etiology, Trends Endocrinol Metab, 2010; 21:214-222.

10. Kennedy BK, Berger SL, Brunet A, Geroscience: linking aging to chronic disease, Cell, 2014; 159:709-713.

11. Christina $P$, Elettra M, Rosalba G, Giovanni B, Roberto P,Epigenetics of aging and disease: a brief overview, Aging Clinical and Experimental Research, 2019; 1-9.
12. Bird A, DNA methylation patterns and epigenetic memory, Genes Dev, 2002; 16:6-21.

13. Abdolmaleky HM, Zhou JR, Thiagalingam S, Smith CL, Epigenetic and pharmacoepigenomic studies of major psychoses and potentials for therapeutics, Pharmacogenomics, 2008; 9(12):18091823.

14. Kim YI, Nutritional epigenetics: impact of folate deficiency on DNA methylation and colon cancer susceptibility, The journal of nutrition, 2005; 135(11):2703-2709.

15. Weaver ICG, Cervoni N, Champagne FA, D'Alessio AC, Sharma S, Seckl JR, Dymov S, Szyf M, Meaney M.J, Epigenetic programming by maternal behavior, Nature neuroscience, 2004; 7(8):847-854.

16. Lu H, Liu X, Deng Y, Qing, DNA methylation a hand behind neurodegenerative diseases, Frontiers in aging neuroscience, 2013; 5:85.

17. Lu C, Thompson CB, Metabolic regulation of epigenetics, Cell metabolism 2012; 16(1):9-17.

18. Berger SL, The complex language of chromatin regulation during transcription, Nature, 2007; 447:407-12.

19. Abrams ST, Zhang N, Manson J, Circulating histones are mediators of trauma-associated lung injury, Am J Respir Crit Care Med, 2013; 187:160-9.

20. Fuchs TA, Kremer Hovinga JA, Schatzberg D, Circulating DNA and myeloperoxidase indicate disease activity in patients with thrombotic microangiopathies, Blood, 2012; 120:1157-64.

21. Ling C, Groop L, Epigenetics: a molecular link between environmental factors and type 2 diabetes, Diabetes 2009; 58(12):2718-2725.

22. Ikeda S, Kong S, Lu J, Bisping E, Zhang H, Allen P, Altered microRNA expression in human heart disease, Physiol Genomics, 2007; 31:367-373.

23. Friedman RC, Farh KKH, Burge CB, Bartel DP, Most mammalian mRNAs are conserved targets of microRNAs, Genome research, 2009; 19(1): 92-105.

24. Goll MG, Bestor TH, Eukaryotic cytosine methyltransferases, Annual review of biochemistry, 2005; 74:481-514.

25. Wang Z, Yao H, Lin S, Zhu X, Shen Z, Lu G, Poon WS, Xie D, Lin MCm, Kung HF, Transcriptional and epigenetic regulation of human microRNAs, Cancer letters, 2013; 331(1):1-10.

26. Ardekani AM, Naeini MM, The role of microRNAs in human diseases, Avicenna journal of medical biotechnology, 2010; 2(4):161-179.

27. TheBasicsonGenesand Genetic Disorders. Available at: https://kidshealth.org/en/teens/genes-genetic-disorders.html.

28. De Kok ., Van Breda S, Manson M, Mechanisms of combined action of different chemo preventive dietary compounds, Eur. J. Nutr., 2008; 47:51-59.

29. Fowke JH, Head and neck cancer, A case for inhibition by isothiocyanates and indoles from cruciferous vegetables, Eur. J. Cancer Prev, 2007; 16(4):348-356.

30. Howells LM, Moiseeva EP, Neal CP, Predicting the physiological relevance of in vitro cancer preventive activities of phytochemicals, Acta Pharmacol. Sin, 2007; 28(9):1274-1304.

31. Knekt $P$, Järvinen $R$,, Seppänen R, Dietary flavonoids and the risk of lung cancer and other malignant neoplasms, Am. J. Epidemiol, 1997; 146(3):223-230.

32. Hardy \& Tollefsbol, Epigenetic diet: impact on the epigenome and cancer, Epigenomics, 2011; 3(4): 503-518.

33. Reamon Buettner SM, Mutschler V, Borlak J, Then extinnovation cyclein toxicogenomics: Environmental epigenetics, Mutat. Res, 2008; 659:158-165.

34. Epigenetics:Fundamental.Availableat:https://www.whatisepigene tics.com/fundamentals/.

35. Elizabeth M, Martin \& Rebecca C. Fry, Environmental Influences on the Epigenome: Exposure Associated DNA Methylation in Human Populations, Annual Review of Public Health, 2018; 39:30.1-30.25.

36. Kim KC, Friso S, Choi SW, DNA methylation, an epigenetic mechanism connecting folate to healthy embryonic development and aging, J. Nutr. Biochem, 2009; 20:917-926.

37. Lillycrop KA,Hoile SP, Grenfell L, Burdge GC, DNA methylation, ageing and the influence of early life nutrition, Proc. Nutr. Soc., 2014; 73:413-421.

38. Jirtle RL, Skinner MK, Environmental epigenomics and disease susceptibility, Nat. Rev. Genet, 2007; 8(4):253-262.

39. McGowan PO, Sasaki A, D'Alessio AC, Epigenetic regulation of the glucocorticoid receptor in human brain associates with childhood abuse, Nat. Neurosci, 2009; 12(3):342-348. 
40. Miller CA, Gavin CF, White JA, Cortical DNA methylation maintains remote memory. Nat. Neurosci, 2010; 13(6):664-666.

41. Miller CA, Sweatt JD, Covalent modification of DNA regulates memory formation, Neuron, 2007; 53(6):857-869.

42. Murgatroyd C, Patchev AV, Wu Y, Dynamic DNA methylation programs persistent adverse effects of early-life stress, Nat. Neurosci, 2009; 12(12):1559-1566.

43. Szyf M, McGowan P, Meaney MJ, The social environment and the epigenome, Environ. Mol. Mutagen, 2008; 49(1):46-60.

44. HowYourThoughtsChangeYourBrain,CellsandGenes.Availableat:ht tps://www.huffpost.com/entry/how-your-thoughts-change-yourbrain-cells-and-genes_b_9516176.Accessed March 24, 2017.

45. Alegría-Torres, Baccarelli A, \& Bollati V, Epigenetics and lifestyle, Epigenomics, 2011; 3(3):267-277.

46. Céline Tiffon, The Impact of Nutrition and Environmental Epigenetics on Human Health and Disease,Int. J. Mol. Sci,2018;19:3425

47. Castro R, Rivera I, Struys EA, Jansen EE, Ravasco P, Camilo ME, Blom HJ, Jakobs C, Tavares de AI, Increased homocysteine and sadenosylhomocysteine concentrations and DNA hypomethylation in vascular disease, Clin Chem, 2003; 49:1292-1296.

48. Baccarelli A, Wright R, Bollati V, Litonjua A, Zanobetti A, Tarantini L, Sparrow D, Vokonas P, Schwartz J, Ischemic heart disease and stroke in relation to blood DNA methylation, Epidemiology, 2010; 21:819-828.

49. Baccarelli A, Cardiovascular epigenetics basic concepts and results from animal and human studies, 2010; 3:567-573.

50. Movassagh M, Choy M, Goddard M, Bennett M, Down T, Foo R, Differential DNA methylation correlates with differential expression of angiogenic factors in human heart failure, PloS One, 2010; 5: e8564.

51. Kaneda R, Takada S, Yamashita Y, Choi Y, Nonaka-Sarukawa M, Soda M, Genome-wide histone methylation profile for heart failure, Genes Cells, 2009; 14:69-77

52. Latronico M, Condorelli G, MicroRNAs and cardiac pathology, Nat Rev Cardiol, 2009; 6:419-429.

53. Wang J, Gong L, Tan Y, Hui R, Wang Y, Hypertensive epigenetics: from DNA methylation to microRNAs, J. Hum. Hypertens, 2015; 29(10): 575-582.

54. Wise IA, Charchar FJ, Epigenetic modifications in essential hypertension, Int. J. Mol. Sci, 2016; 17(4):451.

55. Kalter H, and Warkany J, Medical progress. Congenital malformations: etiologic 927 factors and their role in prevention (first of two parts), N. Engl. J. Med,1983; 308(8):928 424-431.

56. Chang $\mathrm{CP}$, and Bruneau BG, Epigenetics and cardiovascular development, Annu. Rev. Physiol, 2012; 74:41-68.

57. Kelly TK, De Carvalho DD, Jones PP, Epigenetic modifications as therapeutic targets, Nature Biotechnology, 2010; 28(10):10691078.

58. Adam R,Karam V, Delvart V, Grady JO, Mirza D,Klempnauer J, Castaing D., Neuhaus P, Jamieson N, Salizzoni M,Pollard S, Lerut J, Paul A, Garcia-Valdecasas CJ, Rodríguez FS, Burroughs A, Evolution of indications and results of liver transplantation in Europe. A report from the European Liver Transplant Registry (ELTR), Journal of Hepatology, 2012; 57(3):675-688.

59. Jemal A, Bray F, Center MM, Ferlay J, Ward E, and Forman D, "Global cancer statistics," CA: A Cancer Journal for Clinicians,2011;61(2):69-90.

60. Herceg Z, and Paliwal A, "Epigenetic mechanisms in hepatocellular carcinoma: how environmental factors influence the epigenome," Mutation, Research/Reviews in Mutation Research, 2011; 727(3):55-61.

61. Ma L, Chua MS, Andrisani O, and SO S, "Epigenetics in hepatocellular carcinoma: an update and future therapy perspectives, World Journal of Gastroenterology, 2014; 20(2)333345 .

62. Jaenisch R, and Bird A, Epigenetic regulation of gene expression: how the genome integrates intrinsic and environmental signals, Nat Genet, 2003; 245-54.

63. Berger SL, Kouzarides T, Shiekhattar R, Shilatifard A, An operational definition of epigenetics, Genes and development, 2009; 23(7):781-783.

64. Bannister AJ, and Kouzarides T, Regulation of chromatin by histone modifications, Cell Res, 2011; 21(3):381-95.
65. Bartke T, and Kouzarides T, Decoding the chromatin modification landscape,Cell Cycle, 2011; 10(2):182.

66. Bartke T, Nucleosome-interacting proteins regulated by DNA and histone methylation, Cell, 2010; 143(3):470-84.

67. Kouzarides $\mathrm{T}$, Chromatin modifications and their function, Cell, 2007; 128(4):693-705.

68. Zeybel M, Mann DA, and Mann J, Epigenetic modifications as new targets for liver disease therapies, J Hepatol, 2013. 59(6):1349-53.

69. Anstee QM, Seth D, Day CP, Genetic Factors That Affect Risk of Alcoholic and Nonalcoholic Fatty Liver Disease, Gastroenterology, 2016; 150:1728-1744.

70. Roerecke M, Nanau R, Rehm J, Neuman M, Ethnicity matters: A Systematic Review and Meta-Analysis of the Non-Linear Relationship between Alcohol Consumption and Prevalence and Incidence of Hepatic Steatosis, EBioMedicine, 2016; 8:317-330.

71. Abenavoli L, Masarone M, Federico A, Rosato V., Dallio M, Loguercio C, Persico M, Alcoholic hepatitis: pathogenesis, diagnosis and treatment, Rev Recent Clin Trials, 2016; 11:159-166.

72. Luigi Boccuto, Ludovico Abenavoli, Genetic and Epigenetic Profile of Patients with Alcoholic Liver Disease, 2017; 16(4):490-500.

73. Stenvinkel $P$, Karimi M, Johansson $S$, Impact of inflammation on epigenetic DNA methylation - a novel risk factor for cardiovascular disease? J Int Med, 2007; 261:488-499.

74. Sapienza C, Lee J, Powell J, DNA methylation profiling identifies epigenetic differences between diabetes patients with ESRD and diabetes patients without nephropathy, Epigenetics, 2011; 6:2028.

75. Millis RM, Epigenetics and hypertension, Curr Hypertens Rep 2011; 13:21-28.

76. Ho JJ, Marsden PA, Dicer cuts the kidney, J Am Soc Nephrol, 2008; 19:2043-2046.

77. Baldewijns MM, Van Vlodrop IJ, Schouten LJ, Soetekouw PM, De Bruine AP, Van Engeland M, Genetics and epigenetics of renal cell cancer, Biochim Biophys Acta, 2008; 1785: 133-155.

78. Hori Y, Oda Y, Kiyoshima K, Oxidative stress and DNA hypermetylation status in renal cell carcinoma arising in patients on dialysis, J Pathol, 2007; 212: 218-226.

79. Morris MR, Ricketts CJ, Gentle D, Genome-wide methylation analysis identifies epigenetically inactivated candidate tumour suppressor genes in renal cell carcinoma, Epigenetics, 2012; $7(3): 278-290$.

80. Place TL, Fitzgerald MP, Venkataraman S, Aberrant promoter CpG methylation is a mechanism for impaired PHD3 expression in a diverse set of malignant cells, PLoS One, 2011; 6(1):e14617.

81. Arai E, Ushijima S, Fujimoto $\mathrm{H}$, Genome-wide DNA methylation profiles in both precancerous conditions and clear cell renal cell carcinomas are correlated with malignant potential and patient outcome, Carcinogenesis, 2009; 30:214-221.

82. Dalgliesh GL, Furge K, Greenman C, Systematic sequencing of renal carcinoma reveals inactivation of histone modifying genes, Nature, 2010; 463:360-363.

83. Laing ME, Cummins R, O'Grady A, O'Kelly P, Kay EW, Murphy GM, Aberrant DNA methylation associated with MTHFR C677T genetic polymorphism in cutaneous squamous cell carcinoma in renal transplant patients, Br J Dermatol, 2010; 163:345-352.

84. Bechtel W, McGoohan S, Zeisberg EM, Müller GA, Kalbacher $\mathrm{H}$ Salant DJ, Müller CA, Kalluri R, and Zeisberg M, Methylation determines fibroblast activation and fibrogenesis in the kidney, Nat Med, 2010; 16:544-550.

85. Knight JS, Luo W, and O'Dell AA, Peptidylarginine deiminase inhibition reduces vascular damage and modulates innate immune responses in murine models of atherosclerosis, Circ Res, 2014 114:947-56.

86. Shin SM, Yang JH, Ki SH, .Role of the Nrf2-ARE pathway in liver diseases, Oxid Med Cell Longev, (2013); 763257.

87. Haluskova J, Epigenetic studies in human diseases, Folia biologica (Praha), 2010; 56(3):83-96.

88. Susanne Voelter-Mahlknecht, Epigenetic associations in relation to cardiovascular prevention and therapeutics, Clinical Epigenetics, 2016; 8(4):1-17.

89. Mattick JS, Makunin IV, Non-coding RNA, Hum Mol Genet, 2006; 15 (1):17-29. 